\title{
Identification of Restorers with Desirable General Combining Ability from among New Inbred Lines of Sunflower (Helianthus annuus L.)
}

\author{
S. D. Nehru ${ }^{2 *}$, Akshata Timmanna Budihal ${ }^{1}$, M. S. Umar Farooq ${ }^{1 *}$, \\ Y. G. Shadakshari ${ }^{1}$, M. S. Uma ${ }^{2}$ and S. Rameh ${ }^{1}$ \\ ${ }^{1}$ Department of Genetics and Plant Breeding, University of Agricultural Sciences, GKVK, \\ Bangalore, Karnataka, India \\ ${ }^{2}$ AICRP on Sunflower, University of Agricultural Sciences, GKVK, Bangalore, India \\ *Corresponding author
}

\section{A B S T R A C T}

K e y w o r d s
$\begin{aligned} & \text { Fertility restoration, } \\ & \text { Sterility } \\ & \text { maintainance, GCA } \\ & \text { and modifying } \\ & \text { genes }\end{aligned}$
Article Info
Accepted:
18 November 2020
Available Online:
10 December 2020

\section{Introduction}

Sunflower (Helianthus annuus L.) is one of the most important oilseed crop in the world belonging to family Asteraceae with $2 n=2 x=34$ chromosomes. It is primarily grown for edible oil which has high concentration of polyunsaturated fatty acids viz., linoleic and oleic acids and hence considered as good quality oil from the health
The present investigation was carried out in order to study the sterility maintenance and fertility restoration behavior of 47 new inbred lines on three CMS lines and also to estimate the combining ability and heterosis by crossing them in a $\mathrm{L} \times \mathrm{T}$ mating design. The resultant 141 hybrids along with their parents and two checks viz., KBSH-44 and KBSH-53 were evaluated in simple lattice design. Out of 47 inbred lines studied, 10 inbred lines viz., DOR-P-40 (oleic), GMU-456, GMU-716, GMU-746, GMU-759, GMU-773, GMU-785, GMU-1092, $\mathrm{GP}_{6}-952$ and $\mathrm{GP}_{6^{-}} 990$ were identified as common fertility restorers for all the three CMS lines. Common fertility restorers for all the three CMS lines revealed that, even though the CMS lines differed in nuclear background, the fertility restoration genes could be same. It was evident from the present investigation that few inbred lines behaved differentially in the three CMS lines with respect to sterility maintenance and fertility restoration behavior, suggesting the presence of modifying genes, which could influence the fertility restoration thus, resulting in partial fertility. The identified 10 fertility restorer lines with high gca effect could be directly used as male parent in heterosis breeding programme for the development of superior hybrids. 
set and other related problems in the open pollinated varieties. Commercial exploitation of heterosis in sunflower began after the discovery of a stable source of cytoplasmic male sterility CMS PET 1 by Leclercq (1969) in the progeny of cross between Helianthus petiolaris Nutt and cultivated sunflower (cv. Armavirskii 9345) and subsequent identification of fertility restoration genes by Kinman (1970) and Vranceanu and Stoenescu (1971). The discovery of CMS-restorer system led to the shift from population breeding to heterosis breeding (Asif et al., 2013).

The ideal method to develop new restorer lines ( $\mathrm{R}$ line) is by crossing $\mathrm{R} \times \mathrm{R}$ lines from restorer gene pools, which are already identified for fertility restoration in sunflower. In order to identify new restorer lines in sunflower the superior inbred line is crossed with the CMS line and the performance of the male fertility or sterility data of the F1 plants is checked for restorer/maintainer reaction. The inbred which restorers $100 \%$ fertility restoration in CMS line is designated as new restorer line for the CMS line. The superior inbred line is produced either through systematic breeding programme or by selection from agronomically superior germplasm and selfing for 6-7 generations. (Dudhe et al., 2009)

Efficiency of developing high frequency of heterotic CMS-based hybrids for commercial exploitation depends (among others) on the availability of large numbers of fertility restorer lines (R-lines). The R-lines should possess effective restorer genes for complete restoration of fertility in the hybrids developed from CMS lines. From among the identified R-lines, it is desirable to use only those R-lines with significant gca effects. The gca effect is being used as a dependable criterion for selection of parents for use in developing and identifying heterotic hybrids.
The gca effect of a genotype also provide useful clues about the mode of action of genes controlling target traits. It is also useful in predicting the performance of untested hybrids in the absence of sca effects. The support for the use of gca as one of the criteria for choosing parents comes from theoretical results that indicates higher heterosis in the hybrids derived from the parents differing in their gene frequency. Parents differ in their gca due to differences in frequency of genes with additive effects. Under these premises, the present study was carried out with the objective to identify sterility maintainers and fertility restorers of new inbred lines. (Jan et al., 2007).

\section{Materials and Methods}

The material used for the study consisted of three cytoplasmic male sterile lines viz., CMS 234A, NDCMS 2A and CMS 911A, 47 new inbred lines as testers and two standard check hybrids KBSH 44 and KBSH 53. The CMS lines and the testers were collected from AICRP on sunflower, ZARS, UAS, GKVK, Bengaluru.

All the three CMS lines and 47 inbred lines were sown in the field to effect crossing in a Line $\times$ Tester fashion in order to obtain $F_{1}$ 's. Staggered sowing of all CMS lines were carried out three times at an interval of two days to ensure synchronized flowering with inbred lines for crossing. A day prior to opening of first ray floret all the heads of CMS lines and testers were covered with cloth bags in order to prevent undesirable pollination. Pollen from the inbred lines was collected separately in petri dishes with the help of camel hair brush and applied to the flowers of female lines using brushes during morning hours. The pollination was repeated for five to six days in each of the combination to ensure sufficient seed set and simultaneously all inbreds were sib 
pollinated. For investigation on sterility maintenance or fertility restoration reaction and gca of inbreds hybrids were evaluated with two replications along with parents during kharif - 2016.

Experiment was laid out in simple lattice design $(14 \times 14$ involving hybrids, parents and checks). Each genotype was sown in a single row of three-meter length with a row spacing of $60 \mathrm{~cm}$ and $30 \mathrm{~cm}$ between plants within a row.

All the $F_{1}$ progenies at flowering were visually screened for complete male fertility or sterility reaction to know the fertility restoration or sterility maintenance behavior of inbred lines based on the presence or absence of pollen, anther dehiscence and pollen shedding at the anthesis stage in all the plants.

Based on the extent of fertility restored and sterility maintained by the respective inbreds in the crosses, inbreds used in the study were classified as fertility restorers, if all the $F_{1}$ plants were fertile, as sterility maintainers, if all the plants in $F_{1}$ were sterile and those which were segregating for fertility and sterility were considered as partial restorers. Based on this data, $F_{1} s$ were grouped as male sterile or male fertile or partially fertile. Further each inbred lines were classified as sterility maintainers or fertility restorers or partial restorer types for the respective CMS lines.

\section{Pollen fertility test}

During flowering, in each of five randomly selected plants, 10-12 disc florets were collected in the morning hours. These were examined for pollen fertility by preparing anther smears in one per cent acetocarmine stain. Deeply stained pollen grains with good exine were considered as fertile. While, poorly stained and shriveled pollen grains were taken as sterile. By this way different types of reactions of inbred lines were confirmed by pollen fertility test using one per cent acetocarmine (Chaudhary et al., 1981).

\section{Results and Discussion}

The extent of fertility restored and sterility maintained by the respective inbreds in the crosses is presented in Table 1. The new inbred lines which resulted in hybrids with complete fertility were classified as fertility restorers, with completely sterile plants as sterility maintainers and those which resulted in hybrids segregating for both fertility and sterility were considered as partial restorers.

Fertility restoration and sterility maintenance reaction of three CMS lines with 47 inbred lines are presented in Table $2 \mathrm{a} . \mathrm{F}_{1}$ hybrids showing fertility restoration and sterility maintenance reaction is depicted in Figure 1. Differential staining of pollen showing fertile / sterile reaction is depicted in Figure 2.

Out of the 47 pollen parents tested for fertility restoration on three CMS lines, some turned out to be sterility maintainers, some acted as fertility restorers and some as partial restorers. In general out of 141 crosses $40 \mathrm{~F}_{1}$ 's $(29.78$ $\%$ ) were fertile, 82 cross combinations (58.15 $\%)$ were sterile and 19 cross combinations $(13.47 \%)$ resulted in restoring partial fertility for three CMS lines viz., CMS 234A, NDCMS 2A and CMS 911A. It is evident from the data that the probability of identifying the restorers from out of new inbred lines screened with three different CMS lines, is almost same 27.65 per cent for CMS 234A, 25.53 per cent for NDCMS 2A and 31.93 per cent for CMS 911A. The frequency of sterility maintainer / fertility restorer behavior (\%) of inbred lines for three CMS lines is given in the Table $2 b$. 
Table.1 Per cent of male fertility and sterility as indicated by pollen fertility test $(\%)$ in the $\mathrm{F}_{1}$ generation of the crosses between three CMS lines and 47 inbred lines

\begin{tabular}{|c|c|c|c|c|c|c|c|c|c|c|}
\hline \multirow{2}{*}{$\begin{array}{l}\text { Sl. } \\
\text { No. }\end{array}$} & \multirow{2}{*}{ Inbred lines } & \multicolumn{2}{|c|}{ CMS 234A } & \multirow{2}{*}{ Status } & \multicolumn{2}{|c|}{ NDCMS 2A } & \multirow{2}{*}{ Status } & \multicolumn{2}{|c|}{ CMS 911A } & \multirow{2}{*}{ Status } \\
\hline & & Fertility & Sterility & & Fertility & Sterility & & Fertility & Sterility & \\
\hline 1 & AKSFI-78 & 100.00 & 0.00 & Fertile & 33.33 & 66.66 & Partially sterile & 73.33 & 26.66 & $\begin{array}{l}\text { Partially } \\
\text { sterile }\end{array}$ \\
\hline 2 & CGP-10 & 0.00 & 100.00 & Sterile & 0.00 & 100.00 & Sterile & 0.00 & 100.00 & Sterile \\
\hline 3 & DOR-P-40 & 100.00 & 0.00 & Fertile & 100.00 & 0.00 & Fertile & 100.00 & 0.00 & Fertile \\
\hline 4 & DRSI-106 & 0.00 & 100.00 & Sterile & 0.00 & 100.00 & Sterile & 0.00 & 100.00 & Sterile \\
\hline 5 & DRSI-530 & 0.00 & 100.00 & Sterile & 0.00 & 100.00 & Sterile & 0.00 & 100.00 & Sterile \\
\hline 6 & DRSI-550 & 0.00 & 100.00 & Sterile & 0.00 & 100.00 & Sterile & 0.00 & 100.00 & Sterile \\
\hline 7 & GMU-266 & 31.57 & 68.42 & $\begin{array}{l}\text { Partially } \\
\text { sterile }\end{array}$ & 12.50 & 87.25 & Partially sterile & 33.33 & 66.66 & $\begin{array}{l}\text { Partially } \\
\text { sterile }\end{array}$ \\
\hline 8 & GMU-302 & 0.00 & 100.00 & Sterile & 0.00 & 100.00 & Sterile & 0.00 & 100.00 & Sterile \\
\hline 9 & GMU-324 & 0.00 & 100.00 & Sterile & 0.00 & 100.00 & Sterile & 0.00 & 100.00 & Sterile \\
\hline 10 & GMU-325 & 0.00 & 100.00 & Sterile & 0.00 & 100.00 & Sterile & 0.00 & 100.00 & Sterile \\
\hline 11 & GMU-355 & 0.00 & 100.00 & Sterile & 0.00 & 100.00 & Sterile & 0.00 & 100.00 & Sterile \\
\hline 12 & GMU-420 & 0.00 & 100.00 & Sterile & 0.00 & 100.00 & Sterile & 0.00 & 100.00 & Sterile \\
\hline 13 & GMU-452 & 0.00 & 100.00 & Sterile & 0.00 & 100.00 & Sterile & 0.00 & 100.00 & Sterile \\
\hline 14 & GMU-456 & 100.00 & 0.00 & Fertile & 100.00 & 0.00 & Fertile & 100.00 & 0.00 & Fertile \\
\hline 15 & GMU-469 & 21.06 & 78.94 & $\begin{array}{l}\text { Partially } \\
\text { sterile }\end{array}$ & 0.00 & 100.00 & Sterile & 0.00 & 100.00 & Sterile \\
\hline 16 & GMU-485 & 0.00 & 100.00 & Sterile & 0.00 & 100.00 & Sterile & 0.00 & 100.00 & Sterile \\
\hline 17 & GMU-489 & 80.00 & 20.00 & $\begin{array}{l}\text { Partially } \\
\text { sterile }\end{array}$ & 33.33 & 66.66 & Partially sterile & 100 & 0.00 & Fertile \\
\hline 18 & GMU-502 & 0.00 & 100.00 & Sterile & 00.00 & 100.00 & Sterile & 0.00 & 100.00 & Sterile \\
\hline 19 & GMU-563 & 0.00 & 100.00 & Sterile & 0.00 & 100.00 & Sterile & 0.00 & 100.00 & Sterile \\
\hline 20 & GMU-575 & 0.00 & 100.00 & Sterile & 0.00 & 100.00 & Sterile & 20.00 & 80.00 & $\begin{array}{l}\text { Partially } \\
\text { sterile }\end{array}$ \\
\hline 21 & GMU-711 & 0.00 & 100.00 & Sterile & 0.00 & 100.00 & Sterile & 0.00 & 100.00 & Sterile \\
\hline 22 & GMU-716 & 100.00 & 0.00 & Fertile & 100.00 & 0.00 & Fertile & 100.00 & 0.00 & Fertile \\
\hline 23 & GMU-719 & 50.00 & 50.00 & $\begin{array}{l}\text { Partially } \\
\text { sterile }\end{array}$ & 77.77 & 22.22 & Partially sterile & 88.88 & 11.11 & $\begin{array}{l}\text { Partially } \\
\text { sterile }\end{array}$ \\
\hline 24 & GMU-746 & 100.00 & 0.00 & Fertile & 100.00 & 0.00 & Fertile & 100.00 & 0.00 & Fertile \\
\hline
\end{tabular}


Int.J.Curr.Microbiol.App.Sci (2020) 9(12): 2923-2932

\begin{tabular}{|c|c|c|c|c|c|c|c|c|c|c|}
\hline 25 & GMU-759 & 100.00 & 0.00 & Fertile & 100.00 & 0.00 & Fertile & 100.00 & 0.00 & Fertile \\
\hline 26 & GMU-773 & 100.00 & 0.00 & Fertile & 100.00 & 0.00 & Fertile & 100.00 & 0.00 & Fertile \\
\hline 27 & GMU-774 & 52.64 & 47.36 & $\begin{array}{l}\text { Partially } \\
\text { sterile }\end{array}$ & 68.75 & 31.25 & Partially sterile & 90.00 & 10.00 & Fertile \\
\hline 28 & GMU-785 & 100.00 & 0.00 & Fertile & 100.00 & 0.00 & Fertile & 100.00 & 0.00 & Fertile \\
\hline 29 & GMU-1058 & 100.00 & 0.00 & Fertile & 100.00 & 0.00 & Fertile & 0.00 & 100.00 & Sterile \\
\hline 30 & GMU-1060-I & 0.00 & 100 & Sterile & 0.00 & 100.00 & Sterile & 100.00 & 0.00 & Fertile \\
\hline 31 & GMU-1075 & 35.29 & 64.70 & $\begin{array}{l}\text { Partially } \\
\text { sterile }\end{array}$ & 60.00 & 40.00 & Partially sterile & 0.00 & 100.00 & Sterile \\
\hline 32 & GMU-1092 & 100.00 & 0.00 & Fertile & 100.00 & 0.00 & Fertile & 100.00 & 0.00 & Fertile \\
\hline 33 & GP6-18 & 0.00 & 100.00 & Sterile & 0.00 & 100.00 & Sterile & 100.00 & 0.00 & Fertile \\
\hline 34 & GP6-131 & 0.00 & 100.00 & Sterile & 0.00 & 100.00 & Sterile & 0.00 & 100.00 & Sterile \\
\hline 35 & GP6-135 & 100.00 & 0.00 & Fertile & 100.00 & 0.00 & Fertile & 0.00 & 100.00 & Sterile \\
\hline 36 & GP6-217 & 0.00 & 100.00 & Sterile & 0.00 & 100.00 & Sterile & 100.00 & 0.00 & Fertile \\
\hline 37 & GP6-236 & 0.00 & 100.00 & Sterile & 0.00 & 100.00 & Sterile & 0.00 & 100.00 & Sterile \\
\hline 38 & GP6-792 & 72.22 & 27.77 & $\begin{array}{l}\text { Partially } \\
\text { sterile }\end{array}$ & 85.00 & 15.00 & Partially sterile & 0.00 & 100.00 & Sterile \\
\hline 39 & GP6-794 & 0.00 & 100.00 & Sterile & 0.00 & 100.00 & Sterile & 33.33 & 66.66 & $\begin{array}{l}\text { Partially } \\
\text { sterile }\end{array}$ \\
\hline 40 & GP6-799 & 0.00 & 100.00 & Sterile & 0.00 & 100.00 & Sterile & 0.00 & 100.00 & Sterile \\
\hline 41 & GP6-819 & 0.00 & 100.00 & Sterile & 0.00 & 100.00 & Sterile & 0.00 & 100.00 & Sterile \\
\hline 42 & GP6-952 & 100.00 & 0.00 & Fertile & 100.00 & 0.00 & Fertile & 100.00 & 0.00 & Fertile \\
\hline 43 & GP6-990 & 100.00 & 0.00 & Fertile & 100.00 & 0.00 & Fertile & 100.00 & 0.00 & Fertile \\
\hline 44 & IB-55 & 0.00 & 100.00 & Sterile & 0.00 & 100.00 & Sterile & 0.00 & 100.00 & Sterile \\
\hline 45 & IB-107 & 0.00 & 100.00 & Sterile & 0.00 & 100.00 & Sterile & 0.00 & 100.00 & Sterile \\
\hline 46 & PSECO-65 & 0.00 & 100.00 & Sterile & 0.00 & 100.00 & Sterile & 0.00 & 100.00 & Sterile \\
\hline 47 & PSCCO-87 & 0.00 & 100.00 & Sterile & 0.00 & 100.00 & Sterile & 0.00 & 100.00 & Sterile \\
\hline
\end{tabular}


Table.2a Male fertility restoration / male sterility maintainer reaction of new inbred lines under three nuclear backgrounds of PET 1 CMS cytoplasm

\begin{tabular}{|c|c|c|c|c|}
\hline Sl. No. & INBRED LINES & CMS234A & NDCMS 2A & CMS 911A \\
\hline 1 & AKSFI-78 & Restorer & Partial restorer & partial restorer \\
\hline 2 & CGP-10 & Maintainer & Maintainer & Maintainer \\
\hline 3 & DOR-P-40 & Restorer & Restorer & Restorer \\
\hline 4 & DRSI-106 & Maintainer & Maintainer & Maintainer \\
\hline 5 & DRSI-530 & Maintainer & Maintainer & Maintainer \\
\hline 6 & DRSI-550 & Maintainer & Maintainer & Maintainer \\
\hline 7 & GMU-266 & Partial restorer & Partial restorer & Partial restorer \\
\hline 8 & GMU-302 & Maintainer & Maintainer & Maintainer \\
\hline 9 & GMU-324 & Maintainer & Maintainer & Maintainer \\
\hline 10 & GMU-325 & Maintainer & Maintainer & Maintainer \\
\hline 11 & GMU-355 & Maintainer & Maintainer & Maintainer \\
\hline 12 & GMU-420 & Maintainer & Maintainer & Maintainer \\
\hline 13 & GMU-452 & Maintainer & Maintainer & Maintainer \\
\hline 14 & GMU-456 & Restorer & Restorer & Restorer \\
\hline 15 & GMU-469 & Partial restorer & Maintainer & Maintainer \\
\hline 16 & GMU-485 & Maintainer & Maintainer & Maintainer \\
\hline 17 & GMU-489 & Partial restorer & Partial restorer & Restorer \\
\hline 18 & GMU-502 & Maintainer & Maintainer & Maintainer \\
\hline 19 & GMU-563 & Maintainer & Maintainer & Maintainer \\
\hline 20 & GMU-575 & Maintainer & Maintainer & Partial restorer \\
\hline 21 & GMU-711 & Maintainer & Maintainer & Maintainer \\
\hline 22 & GMU-716 & Restorer & Restorer & Restorer \\
\hline 23 & GMU-719 & Partial restorer & Partial restorer & Partial restorer \\
\hline 24 & GMU-746 & Restorer & Restorer & Restorer \\
\hline 25 & GMU-759 & Restorer & Restorer & Restorer \\
\hline 26 & GMU-773 & Restorer & Restorer & Restorer \\
\hline 27 & GMU-774 & Partial restorer & Partial restorer & Restorer \\
\hline 28 & GMU-785 & Restorer & Restorer & Restorer \\
\hline 29 & GMU-1058 & Restorer & Restorer & Maintainer \\
\hline 30 & GMU-1060-I & Maintainer & Maintainer & Restorer \\
\hline 31 & GMU-1075 & Partial restorer & Partial restorer & Maintainer \\
\hline 32 & GMU-1092 & Restorer & Restorer & Restorer \\
\hline 33 & GP6-18 & Maintainer & Maintainer & Restorer \\
\hline 34 & GP6-131 & Maintainer & Maintainer & Maintainer \\
\hline 35 & GP6-135 & Restorer & Restorer & Maintainer \\
\hline 36 & GP6-217 & Maintainer & Maintainer & Restorer \\
\hline 37 & GP6-236 & Maintainer & Maintainer & Maintainer \\
\hline 38 & GP6-792 & Partial restorer & Partial restorer & Maintainer \\
\hline 39 & GP6-794 & Maintainer & Maintainer & Partial restorer \\
\hline 40 & GP6-799 & Maintainer & Maintainer & Maintainer \\
\hline 41 & GP6-819 & Maintainer & Maintainer & Maintainer \\
\hline 42 & GP6-952 & Restorer & Restorer & Restorer \\
\hline 43 & GP6-990 & Restorer & Restorer & Restorer \\
\hline 44 & IB-55 & Maintainer & Maintainer & Maintainer \\
\hline 45 & IB-107 & Maintainer & Maintainer & Maintainer \\
\hline 46 & PSECO-65 & Maintainer & Maintainer & Maintainer \\
\hline 47 & PSCCO-87 & Maintainer & Maintainer & Maintainer \\
\hline
\end{tabular}


Table.2b Frequencies of maintainers, restorers and partial restorer lines for three nuclear backgrounds of PET 1 CMS cytoplasm

\begin{tabular}{|l|l|l|l|l|}
\hline CMS lines & $\begin{array}{l}\text { Inbred } \\
\text { evaluated }\end{array}$ & lines & \multicolumn{4}{|l|}{ Number of inbred lines behaved as } \\
\cline { 2 - 5 } & 47 & Restorers & Maintainers & Partial restorers \\
\hline CMS 234A & $47(27.65 \%)$ & $27(57.44 \%)$ & $\mathbf{7}(\mathbf{1 4 . 8 9} \%)$ \\
\hline NDCMS 2A & 47 & $12(25.53 \%)$ & $28(59.57 \%)$ & $\mathbf{7}(\mathbf{1 4 . 8 9} \%)$ \\
\hline CMS 911A & $\mathbf{4 7}$ & $\mathbf{1 5}(\mathbf{3 1 . 9 1} \%)$ & $\mathbf{2 7}(\mathbf{5 7 . 4 4} \%)$ & $\mathbf{5}(\mathbf{1 0 . 6 3} \%)$ \\
\hline
\end{tabular}

Figures in the parenthesis indicate per cent estimates

Table.3 Common sterility maintainer and fertility restorer inbred lines for all the three CMS lines in sunflower

\begin{tabular}{|c|c|c|}
\hline & Inbred lines & Total \\
\hline $\begin{array}{l}\text { Common } \\
\text { Restorers }\end{array}$ & $\begin{array}{l}\text { DOR-P-40 (oleic), GMU-456, GMU- } \\
\text { 716, GMU-746, GMU-759, GMU- } \\
\text { 773, GMU- 785, GMU-1092, GP } 6^{-} \\
\text {952, GP } 6^{-} 990 .\end{array}$ & 10 \\
\hline $\begin{array}{l}\text { Common } \\
\text { maintainers }\end{array}$ & $\begin{array}{l}\text { CGP-10, DRSI-106, DRSI-530, DRSI- } \\
\text { 550, GMU-302, GMU-324, GMU-325, } \\
\text { GMU- 355, GMU-420, GMU-452, } \\
\text { GMU-485, GMU-502, GMU-563, } \\
\text { GMU-711, GP }-131, \text { GP }_{6}-236, \mathrm{GP}_{6}- \\
\text { 799, GP }-819 \text {, IB-55, IB-107, PSECO- } \\
\text { 65, PSECO-87. }\end{array}$ & 22 \\
\hline
\end{tabular}

Fig.1 Fertile and sterile reaction in $\mathrm{F}_{1}$ hybrids

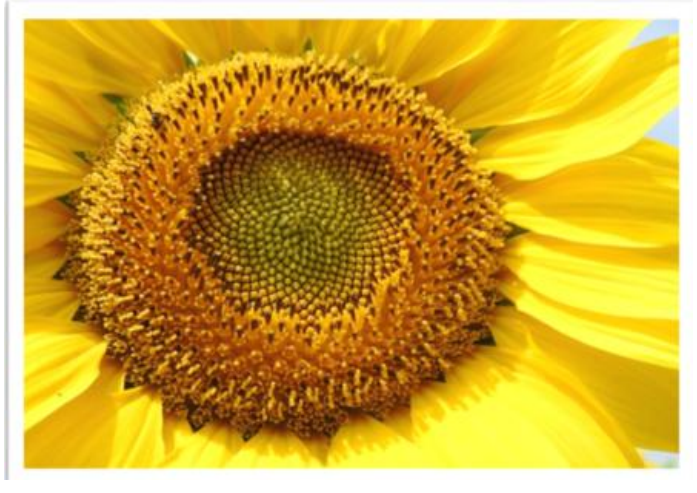

FERTILE REACTION IN F 1 HYBRIDS

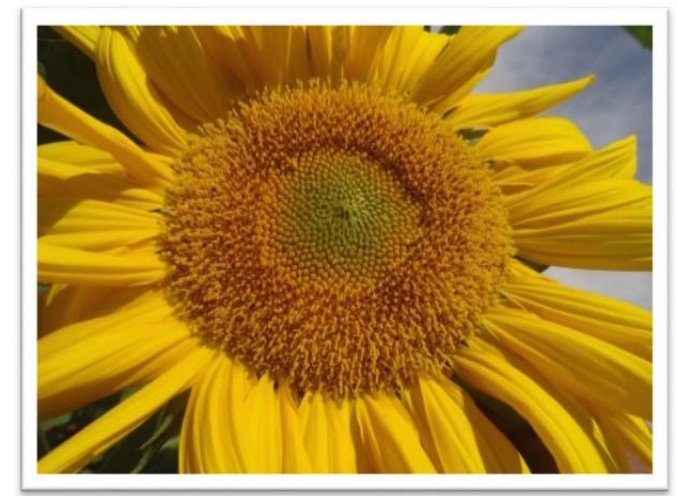

STERILE REACTION IN F 1 HYBRIDS 
Fig.2 Staining of pollen using acetocarmine depicting fertile and sterile pollen

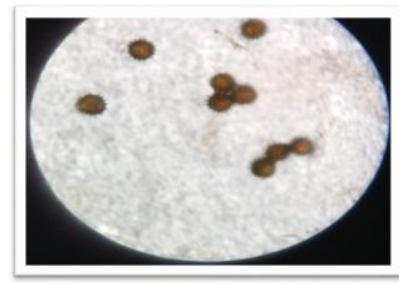

FERTILE POLLEN

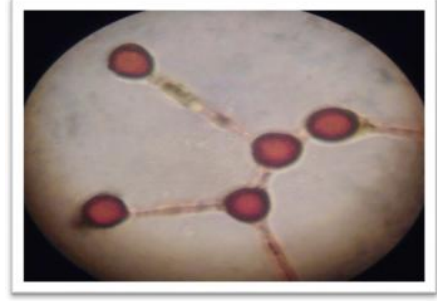

STERILE POLLEN

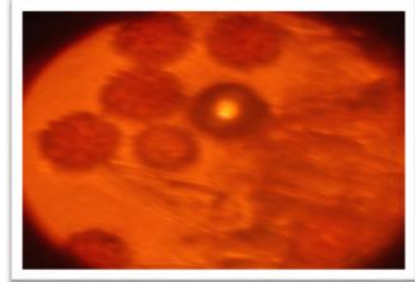

PARTIAL FERTILE POLLEN
Sunflower breeders have extensively exploited the PET 1 source of male sterility to develop high yielding hybrids in cross combinations. Among the lines CMS 234A, NDCMS 2A and CMS 911A were widely used in present day heterosis breeding programme. Hence, attempts are made to identify new restorer lines to exploit heterosis for same CMS back ground.

Out of 47 inbred lines studied, 10 inbred lines viz., DOR-P-40 (oleic), GMU-456, GMU716, GMU-746, GMU-759, GMU-773, GMU-785, GMU-1092, GP $6^{-} 952$, and $\mathrm{GP}_{6^{-}}$ 990 showed fertility restoration in the $\mathrm{F}_{1}$ 's derived from three CMS lines. Whereas twenty inbred lines viz., CGP-10, DRSI-106, DRSI-530, DRSI-550, GMU-302, GMU-324, GMU-325, GMU-355, GMU-420, GMU-452, GMU-485, GMU-502, GMU-563， GMU711, $\mathrm{GP}_{6}-131, \mathrm{GP}_{6}-236, \mathrm{GP}_{6}-799, \mathrm{GP}_{6}-819$, IB-55, IB-107, PSECO-65 and PSECO-87 were sterility maintainers in $\mathrm{F}_{1}$ 's of all three CMS lines. Common sterility maintainer and fertility restorer inbred lines with all the three CMS lines is presented in Table 3. However, majority of the inbreds tested were sterility maintainers of CMS sources suggesting the absence of fertility restoration genes in these inbreds. This indicated that, though CMS lines differed by nuclear background, the fertility restoring genes could be same. Similar results were obtained by Virupakshappa and Jayarame Gowda (1996), Neelima et al., (2011), Meena and Sujatha (2013), Satish Chandra and Sudheer Kumar (2011).The inbreds which were grouped as maintainers after testing for combining ability coupled with good agronomic performance could be used to develop heterotic hybrids (Yogesh et al., 2007) or to develop new CMS lines (Sujatha and Vishnuvardhan Reddy, 2008).

The results revealed that the inbreds GMU1058 and $\mathrm{GP}_{6}-135$ were fertility restorers on two CMS background CMS viz., NDCMS 2A and CMS 234A. The inbreds GMU-575, GMU-1060-I, GP $6^{-18}, \mathrm{GP}_{6}-217$ and $\mathrm{GP}_{6}-794$ were maintainers for two CMS lines viz., CMS 234A and NDCMS 2A. However, in case of line CMS 911A, the inbreds GMU489, GMU-774, GMU-1060-I, GP $6-18$ and $\mathrm{GP}_{6}-217$ were complete fertility restorers, 
however the inbreds GMU-575 and $\mathrm{GP}_{6}-794$ were partial restorers. Hence it is evident that with respect to maintenance and restoration of fertility, few inbreds differed in all three CMS background, suggesting the influence of modifying genes on fertility restoration which results in partial fertility (Rukmini Devi et al., 2006; Dudhe et al., 2009). This indicates the presence of partial fertility restorer in a heterozygous condition or a possible contamination with the unknown pollen (Yogesh et al., 2007).

It was observed that GMU-774, GMU-489, GMU-1075, and $\mathrm{GP}_{6}-792$ showed partially fertility reaction for two lines viz., CMS 234A and NDCMS 2A, whereas the inbreds GMU774, GMU-489 were fertility restorers and GMU-1075, GP 6 -792 were maintainers for CMS 911A background. The inbred AKSFI78 was found to be partial fertility restorer for NDCMS 2A, CMS 911A and complete fertility restorer for CMS 234A respectively. The inbred GMU-469 was partial fertility restorer for CMS 234A, whereas for NDCMS 2A, CMS 911A was sterility maintainer. Similar reports were made by Wankhade et al., (2004). It is evident from present investigation that few inbreds behaved differently with the three CMS lines with respect to maintainance and restoration of fertility suggesting the influence of modifying genes on fertility restoration, resulting in partial fertility (Rukmini Devi et al., 2006; Dudhe et al., 2009). The inheritance of partial restoration may be complex and highly dependent on environmental condition. These findings are in agreement with those of Rukmini Devi et al., (2006). Based on general combining ability effects of the inbred lines which were identified as promising fertility restorers and sterility maintainers in different nuclear background could be utilized for hybridization programme. Worth converting inbreds into male sterile versions could be identified. These results are similar to those reported by Yogesh et al., (2007) and Sujatha and Vishnuvardhan Reddy (2008).

In conclusion the common fertility restorers for all the three CMS lines revealed that, even though the CMS lines differed in nuclear background, the fertility restoration genes could be same. It was evident from the present investigation that few inbred lines behaved differentially in the three CMS lines with respect to sterility maintenance and fertility restoration behavior, suggesting the presence of modifying genes, which could influence the fertility restoration thus, resulting in partial fertility. The 10 fertility restorer lines with high $g c a$ effect identified could be directly used as male parent in heterosis breeding programme for the development of superior hybrids. Among 22 sterility maintainer lines, few promising lines with high gca effect could be converted into new CMS lines through backcross breeding.

\section{References}

Asif, M., Shadakshari, Y. G., Satheesh Naik, S. J., Venkatesha, K. T., Vijayakumar K. V. and Basavaprabhu N. M., 2013, Combining ability studies for seed yield and it's contributing traits in sunflower (Helianthus annuus L.). Int. J. Plant Sci., 8: 19-24.

Aslam, S., Mulk Khan, S., Saleem, M., Qureshi, S. A., Khan, A., Islam, M. AND KHAN, S., 2010, Heterosis for the improvement of oil quality in sunflower (Helianthus annuus L.). Pakistan. J. Bot., 42(2): 1003-1008.

Chaudhary, R. C., Virmani, S. S. and Khush, G. S. 1981. Pattern of pollen abortion in some cytoplasmic genetic male sterile lines of rice. Oryza, 88(3): 140142.

Dudhe M. Y., Moon M. K. and Lande S. S., 2009, Evaluation of restorer lines for heterosis studies on sunflower, 
(Helianthus annuus L.). J. Oilseeds Res., 26: 140- 141.

Jan, C. C. and Vick, B. A., 2007, Inheritance and allelic relationships of fertility restoration genes for seven new sources of male sterile cytoplasm in sunflower. Plant Breed., 126: 213-217.

Kinman, M. L., 1970, New development in the USDA and state experiment station, sunflower breeding programme. Proceedings of the Fourth International sunflower Conference, Memphis, Tennessa, pp. 181-183.

Leclercq, P., 1969, Line sterile cytoplasmique chezktournesol. Ann. Amelior Planta, 12: 99-106.

Meena, H. P. and Sujatha., 2013, Maintainer / restorer identification for different CMS lines in sunflower. J. Oilseeds, 30(2): 134-137.

Neelima, S., Kumar K. and Ashok., 2011, Maintainer / restorer behavior of different inbreds to CMS 234A line in sunflower (Helianthus annuus L.). Agric. Sci. Dig., 31(3): 214-216.

Rukminidevi Devi, K., Ranganatha, A. R. G. and Ganesh, M., 2006, Combining ability and heterosis for seed yield and its attributes in sunflower. Agric. Sci. Dig., 25(1): 11-14.
SATISH CHANDRA, B. AND SUDHEER Kumar. S., 2011, Combining ability studies for development of new hybrids over environments in sunflower (Helianthus annuиs L.). J. Agric. Sci., 3(2): 23-25.

Sujatha, M. and Vishnuvardhan Reddy, A., 2008, Identification of fertility restorers / maintainers in sunflower (Helianthus annuus L.). J. Oilseeds Res., 25(2): 181-182.

Virupakshappa, K. and Jayarame Gowda., 1996, Utilization of new CMS sources in sunflower breeding, In: Proc. 14th Int. Sunflower Conf., 1-2pp.

Vranceanu, A. V. and Stoenescu, F. M., 1971, Pollen fertility restorer gene from cultivated sunflower. Euphytica, 20: 536-541.

Wankhade, R. R., Rajput, J. C., Halakude, I. S., Kulkarni, M. P., Sawarkar, N. W. and Dalvi, P. A., 2004, Identification of fertility restorers for CMS lines in sunflower (Helianthus annuus L.). J. Oilseeds Res., 21: 156-157.

Yogesh, L. N., Gangappa, E., Girish, G. and Manjunath, Y. S., 2007, Combining ability studies in sunflower. Indian $J$. Crop Sci., 2(1): 239-241.

\section{How to cite this article:}

Nehru, S. D., Akshata Timmanna Budihal, M. S. Umar Farooq, YG. Shadakshari, M. S. Uma and Rameh, S. 2020. Identification of Restorers with Desirable General Combining Ability from among New Inbred Lines of Sunflower (Helianthus annuиs L.). Int.J.Curr.Microbiol.App.Sci. 9(12): 2923-2932. doi: https://doi.org/10.20546/ijcmas.2020.912.347 